\title{
The breeding ecology of the pipefish Nerophis lumbriciformis and its relation to latitude and water temperature
}

\author{
N. Monteiro* $*^{\ddagger}$ V.C. Almada ${ }^{\dagger}$, A.M. Santos* and M.N. Vieira* \\ * Departamento de Zoologia e Antropologia, Faculdade de Ciências, Universidade do Porto, \\ Praça Gomes Teixeira, 4099-002 Porto, Portugal. ${ }^{\dagger}$ Instituto Superior de Psicologia Aplicada, \\ Rua Jardim do Tabaco, 44, 1149-041 Lisboa, Portugal. ${ }^{\ddagger}$ Corresponding author, e-mail: nmonteir@fc.up.pt
}

\begin{abstract}
The breeding season of Nerophis lumbriciformis (Pisces: Syngnathidae), has not yet been determined for the southernmost part of its range. A total of 863 individuals were examined between March 1997 and November 1999. In Portugal, the breeding season of this species occurs throughout the year, with a marked reduction during summer and autumn, whilst in Britain it occurs from May to September. Despite these temporal differences, the water temperature at which breeding takes place is similar in the two areas $\left(13-16^{\circ} \mathrm{C}\right)$. Together with preliminary laboratory observations with animals kept at different temperatures, these data support the hypothesis that the decrease in breeding activity during summer and autumn in Portugal is due to an inhibitory effect of high water temperature.
\end{abstract}

\section{INTRODUCTION}

Nerophis lumbriciformis (Jenyns, 1835) is a small and slender pipefish, commonly found in the rocky intertidal to about $30 \mathrm{~m}$ (Wheeler, 1969; Dawson, 1986), mainly among seaweeds. Its distribution ranges from the Atlantic coast of Norway to the Kattegat, and from Belgium southwards to Morocco (Dawson, 1986). During the breeding season, males brood their offspring attached to their flattened ventral surface. Throughout gestation parental care is exclusively paternal. The newborn juveniles are freeswimming and no further care is provided (personal observation).

Although the breeding season of $\mathcal{N}$. lumbriciformis has been reported for the British Isles (May to September, with a peak in June-August (Wheeler, 1969)), data concerning the southernmost part of its range are missing. This information is however useful at a time when problems associated with global warming require a better understanding of the way temperature affects the breeding process of temperate inshore fish.

\section{MATERIALS AND METHODS}

Data were collected from the upper limit of the sublittoral zone, at Viana do Castelo $\left(41^{\circ} 41^{\prime} 45^{\prime \prime} \mathrm{N}\right.$ $\left.8^{\circ} 51^{\prime} 09^{\prime \prime} \mathrm{W}\right)$, Portugal, between March 1997 and November 1999. Sampling was performed using nondestructive methods. Individuals were collected by hand, without the use of any anaesthetic, mainly under loose stones. Prior to their release, the fish were sexed, measured, and the presence and number of eggs attached to the male's ventral surface was recorded. Only fish bigger than $8.5 \mathrm{~cm}$ were used to determine the breeding season, since it seems to be the minimum size suitable for reproduction (males smaller than $8.5 \mathrm{~cm}$ did not show flattened ventral surfaces, and the smallest pregnant male caught had approximately this size).
Wheeler (1969) states that the breeding season of Nerophis lumbriciformis around the British Isles lasts from June to August (exceptionally from May to September). He does not state what his information base was and we were not able to get the primary sources on this subject. Indeed, subsequent authors (e.g. Dawson, 1986; Villanueva et al., 1995) consistently refer only to the work of Wheeler. Assuming that the breeding season stated by Wheeler was valid for the years 1967-1969 (to allow for the time needed for the edition of the book), we used the data on sea surface water temperature from Plymouth (Southward \& Butler, 1972), for those years (mean monthly sea surface water temperature), as an example of a location in the south of the British shore to contrast with the data on the temperatures on our study during the observation period. This is likely to be a conservative choice because temperature at stations located further north around Britain must present contrasts even more extreme than the one we have found.

\section{RESULTS}

A total of 863 individuals was examined (this value probably includes recaptures). The average number of eggs found was $49(\mathrm{~N}=114$; range $=18-84$; average $=48.71$; $\mathrm{SD}=10.84$ ).

Figure 1 depicts the monthly percentage of pregnant males, clearly showing that, in Portugal, breeding takes place throughout the year, with a marked reduction during summer and autumn. In Figure 2 the breeding season of Nerophis lumbriciformis in Portugal and Britain, is presented in relation with the patterns of sea temperature variation. A detailed inspection shows that, in both areas, reproduction takes place at approximately similar temperatures $\left(13-16^{\circ} \mathrm{C}\right)$, but this temperature range occurs in Portugal over a more extended period. It is also visible that, in summer and autumn, when water temperature reaches values above $16^{\circ} \mathrm{C}$, there is a marked reduction in the percentage of pregnant males. Since gestation 


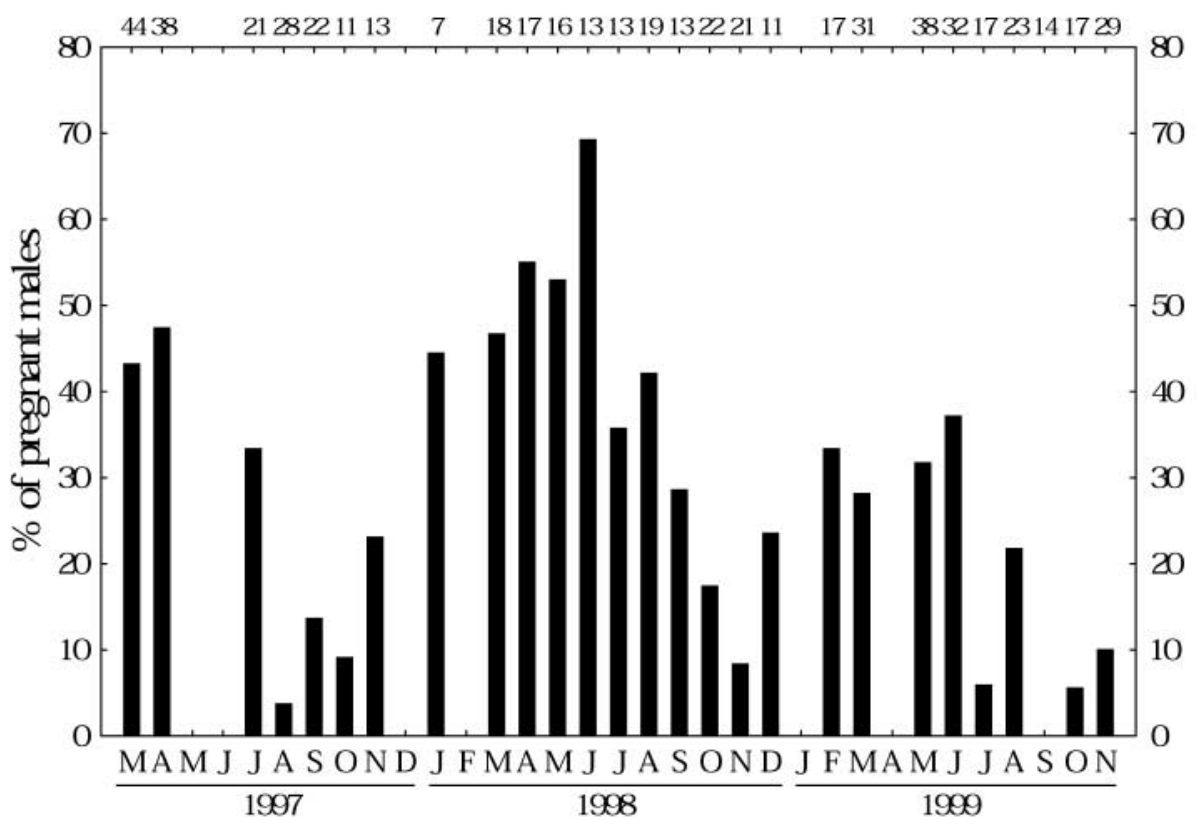

Figure 1. Percentage of pregnant males. The number of adult individuals $(\mathrm{N})$ is presented in the top of the bar graph.

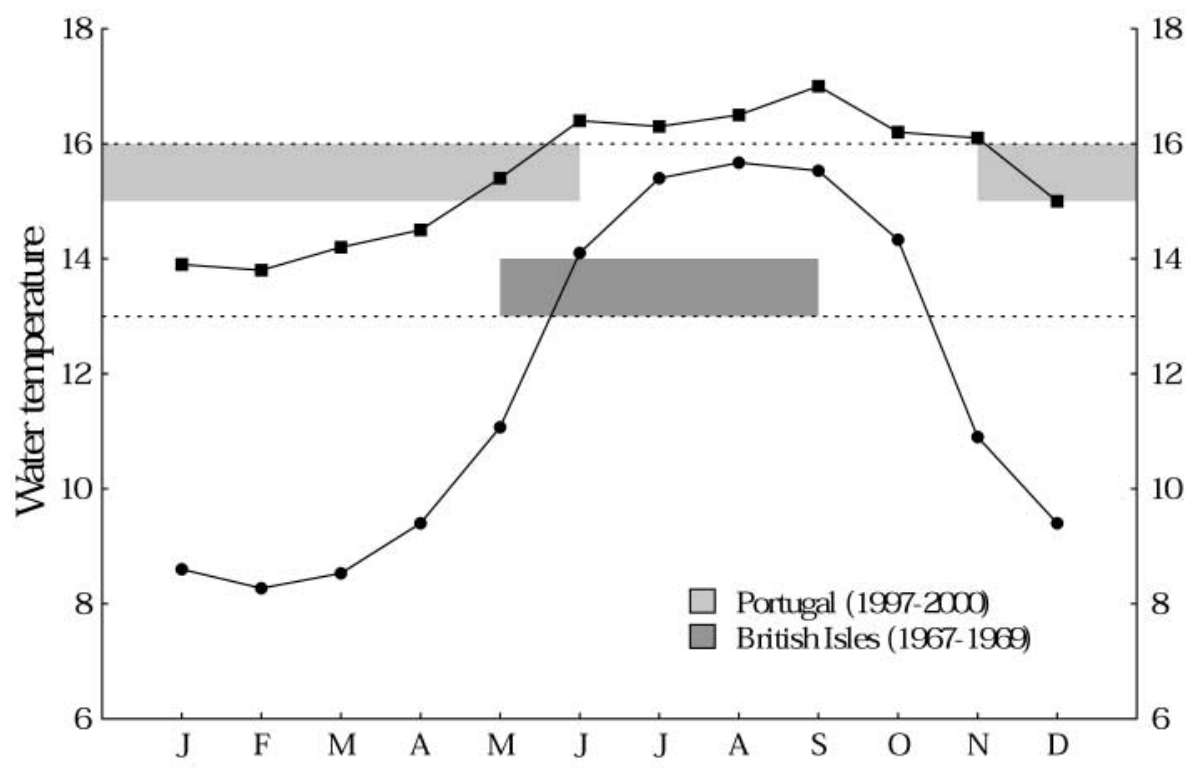

Figure 2. Mean monthly surface water temperature from Oporto (1997-1999; Portugal) (filled square) and Plymouth (1967-1969; British Isles) (filled circle). The breeding season, in Portugal and Britain (Wheeler, 1969) is also schematically presented.

lasts approximately 30 days (Monteiro et al., in press) it is probably more adequate to compare the percentage of pregnant males with reference to the water temperature recorded in the previous month. We found a highly significant difference in the percentage of pregnant males between dates at which the water temperature, recorded one month before, was above $16^{\circ} \mathrm{C}$ (median=15.909; 25 th quartile $=7.487$; 75 th quartile $=32.051$ ), and those for which the water temperature, in the previous month, was lower $\quad($ median $=46.667 ; 25$ th $q$ quartile $=35.294 ; 75$ th quartile $=57.143) \quad($ Mann - Whitney $\quad U$-test,$\quad \mathrm{N} 1=11$ sampling months, $\mathrm{N} 2=16$ sampling months, $\mathrm{U}=12$, $\mathrm{Z}=3,75, P<0,001)$.

\section{DISCUSSION}

The results suggest that a fish that breeds in the summer in Britain, is a predominantly winter and spring breeder in Portugal. Moreover, temperatures above $16^{\circ} \mathrm{C}$ may inhibit reproduction in this species. In preliminary laboratory observations, three groups of $\sim 20$ fish each were kept for about ten months at temperatures below $15^{\circ} \mathrm{C}$, with a regular presence of pregnant males. A rise of temperature to $16^{\circ} \mathrm{C}$ was followed by the cessation of all spawnings and, in a few weeks, no pregnant males were found. Spawnings and pregnancies were resumed when the previous lower temperature was restored. This pattern was recorded 
when these temperature changes were replicated. Therefore, these preliminary data support the hypothesis that the decrease in breeding activity during summer and autumn in Portugal is due to an inhibitory effect of high water temperature.

Differences of several months in the breeding season, in Portugal and Britain, have also been reported for Coryphoblennius galerita (Almada et al., 1996), Gobius paganellus and Gobius cobitis (Faria \& Almada, 1995), and Lipophrys pholis (Almada et al., 1990; Faria et al., 1996). Almada et al. (1990) suggested that L. pholis, which is also a late spring and summer breeder in Britain, and an autumn, winter and spring breeder in Portugal, may stop breeding due to an inhibitory effect of increased water temperatures that prevail from May through summer.

Conover (1992) proposed an adaptationist hypothesis to explain the differences in breeding seasons of fish living at different latitudes. According to Conover, the winter mortality of juveniles should select for the production of strong and large juveniles that would have a greater chance of surviving winter. Thus, at a given latitude, breeding should cease when there is still enough time for larval and juvenile growth before the winter, a condition that would take place sooner at higher latitudes since, at lower latitudes, sufficiently high temperatures for feeding and growth would persist for a longer period. Nevertheless, in Nerophis lumbriciformis, as in L. pholis, the end of the breeding season occurs earlier in Portugal than in Britain, which contradicts Conover's model. Both species decrease or stop breeding at early summer in Portugal, when many other species whose ranges have their distributional centres at lower latitudes are breeding actively (personal observation). If temperatures above a critical threshold inhibit reproduction, as suggested above, a simple nonadaptive hypothesis based on phylogenetic considerations, to explain the timing of the breeding season, particularly near the limits of the species ranges, cannot be ruled out. Such a marked shift in the timing of breeding with latitude provides circumstancial evidence that temperature is probably a much more effective factor than photoperiod in the control of reproduction.
We would like to thank everyone who helped during the fieldwork, especially Sandra Quinteira, João Bacelo, Sara da Mata and António Pereira. We would also like to thank three referees that, with their criticism and suggestions, gave us substantial contribution to the improvement of the manuscript, as well as Dr Ann Pulsford for her editorial comments and suggestions. Professor Vitor Almada's participation was partially supported by CLIPE (Efeitos Climáticos na Ecologia de Peixes LitoraisPRAXIS 3/3.2/EMG/1957/95) and Programa Plurianual.

\section{REFERENGES}

Almada, V.C., Barata, E.N., Gonçalves, E.J. \& Oliveira, R.F., 1990. On the breeding season of Lipophrys pholis (Pisces: Blenniidae) at Arrábida, Portugal. Fournal of the Marine Biological Association of the United Kingdom, 70, 913-916.

Almada, V.G., Carreiro, H., Faria, C. \& Gonçalves, E.J., 1996. The breeding season of Coryphoblennius galerita in Portuguese waters. Journal of Fish Biology, 48, 295-297.

Conover, D.O., 1992. Seasonality and the scheduling of life history at different latitudes. Fournal of Fish Biology, 41B, 161-178.

Dawson, C.E., 1986. Syngnathidae. In Fishes of the northeastern Atlantic and the Mediterranean (ed. P.J.P. Whitehead et al.), pp. 628-639. Paris: Unesco.

Faria, G. \& Almada, V.C., 1995. Some aspects of the breeding season of Gobius cobitis Pallas and Gobius paganellus L. in the west coast of Portugal. Arquivos do Museu Bocage, 29, 463-471.

Faria, C., Almada, V.C. \& Gonçalves, E.J., 1996. Juvenile recruitment, growth and maturation of Lipophrys pholis (Pisces: Blenniidae), from the west coast of Portugal. Fournal of Fish Biology, 49, 727-730.

Monteiro, N.M., Vieira, M.N. \& Almada, V.C., in press. The courtship behaviour in the pipefish Nerophis lumbriciformis. Reflections of an adaptation to intertidal life. Acta Ethologica.

Southward, A.J. \& Butler, E.I., 1972. A note on further changes of the sea temperature in the Plymouth area. Fournal of the Marine Biological Association of the United Kingdom, 52, 931-937.

Villanueva, X.L., Vázquez, X. \& Escudero, H.A., 1995. Peixes do mar de Galicia (III). Xerais.

Wheeler, A., 1969. The fishes of the British Isles and north west Europe. Macmillan.

Wheeler, A., 1978. Key to the fishes of Northern Europe. Frederick Warne.

Submitted 1 December 2000. Accepted 15 October 2001. 